\title{
Self-nanoemulsifying drug delivery system (SNEDDS) of Amomum compactum essential oil: Design, formulation, and characterization
}

\author{
Tri Ujilestari ${ }^{1}$, Ronny Martien ${ }^{3}$, Bambang Ariyadi², Nanung Danar Dono ${ }^{1}$, Zuprizal $^{1 *}$ \\ ${ }^{1}$ Department of Animal Nutrition and Feed Science, Faculty of Animal Science, Universitas Gadjah Mada, Yogyakarta, Indonesia. \\ ${ }^{2}$ Department of Animal Production, Faculty of Animal Science, Universitas Gadjah Mada, Yogyakarta, Indonesia. \\ ${ }^{3}$ Department of Pharmaceutics, Faculty of Pharmacy, Universitas Gadjah Mada, Yogyakarta, Indonesia.
}

\section{ARTICLE INFO \\ Article history: \\ Received on: $14 / 03 / 2018$ \\ Accepted on: 25/05/2018 \\ Available online: 29/06/2018}

\section{Key words:}

Amomum compactum, essential oil, self-nano emulsifying drug delivery system, D-optimal mixture design.

\begin{tabular}{l}
\hline ABSTRACT \\
\hline The main purpose of this study was to formulate and to characterize a self-nanoemulsifying drug delivery systems \\
of cardamom (Amomum compactum) essential oil. The optimum formula was analyzed using a D-Optimal mixture \\
designed by varying concentrations of oil component (Amomum compactum essential oil and virgin coconut oil), \\
Tween 80 , and polyethylene glycol 400 (PEG 400 ) ( $/ \mathrm{v}$ ) using a Design Expert $囚$ Ver. 7.1 .5 . Emulsification time and \\
transmittance were selected as responses for optimization. The optimum formula was characterized by droplet size, \\
zeta potential, viscosity, thermodynamic stability, and morphology using Transmission Electron Microscopy. SNEDDS \\
of Amomum compactum essential oil was successfully formulated to SNEDDS using $10 \%$ of Amomum compactum \\
essential oil, $10 \%$ of virgin coconut oil, $65.71 \%$ of Tween 80 , and $14.29 \%$ of PEG 400 . The characterization result \\
showed the percent transmittance $99.37 \pm 0.06$, emulsification time $46.38 \pm 0.61 \mathrm{~s}$, the average droplet size $13.97 \pm$ \\
0.31 nm with PI $0.06 \pm 0.05$, zeta potential -28.8 to $-45.9 \mathrm{mV}$, viscosity $187.5 \pm 0 \mathrm{mPa} \cdot \mathrm{s}$, passed the thermodynamic \\
stress tests, and indicated spherical shape. The study revealed that the formulation has increased solubility and stability \\
of Amomum compactum essential oil.
\end{tabular}

\section{INTRODUCTION}

Colonization of microbes in the gastrointestinal tract has an impact on the performance of broiler chickens (Dibner et al., 2008). Pathogenic microbes produce toxins which damage the physical structure of the small intestine cell wall, which is crucial in the micronutrient absorption process. Infection of bacteria in poultry and livestock production could be prevented with antibiotics (Apata, 2009). However, antibiotics as growth promoters have already restricted in many countries (Verstegen and Williams, 2002).

Essential oil could be used as an antibiotic replacement because of its ability to inhibit the growth of pathogenic bacteria (Akhtar et al., 2013). The major component Amomum compactum essential oil is composed of 1.8 cineole (eucalyptol) 59.3\%;

\section{"Corresponding Author}

Prof. Dr. Ir. Zuprizal, DEA, Department of Animal Nutrition and Feed Science, Faculty of Animal Science, Universitas Gadjah Mada, Yogyakarta, Indonesia.E-mail: zuprizal@ugm.ac.id d-limonene $29 \%$; $\alpha$-pinene $6.5 \%$; $\beta$-pinene $4.8 \%$; and $\alpha$-terpineol $0.4 \%$ (Huang et al., 1999). The main constituent 1,8 cineole is known to have strong antibacterial activity. The 1,8 cineole has been reported to inhibit the growth of enteric bacteria Escherichia coli O157:H7, Salmonella typhimurium, Klebsiella pneumoniae, Enterobacter aerogenes, and Methicillin-resistant Staphylococcus aureus (Nanasombat and Lohasupthawee, 2005; Zengin and Baysal, 2014; Jamil et al., 2016).

Essential oil also enhances the production of digestive secretions, an antioxidant component, and improve the immunity (Zeng et al., 2015). However, their potency as an alternative to replace in-feed antibiotic decrease due to their volatile nature, insoluble in water and unstable (Jamil et al., 2016). Nanotechnology is an attractive technology in functional applications in the interdisciplinary field. Generally, nanotechnology has a size of $10^{-9} \mathrm{~m}$. The size of nanoemulsion ranges 1-100 $\mathrm{nm}$ (Neethirajan and Jayas, 2011). Nanotechnology in essential oils has provided the benefits that are the active compounds more easily absorbed and more efficiently transported to the site of infection (Natrajan et al., 2015). Self- 
nanoemulsifying drug delivery systems have been proposed because of their ability to increase solubility and stability of essential oil-based formulations (Pedro et al., 2013).

Amomum compactum essential oil is limited orally application because of its low oral bioavailability. In this investigation, a new self-nanoemulsifying drug delivery system was developed to improve the solubility and stability of Amomum compactum essential oil.

\section{MATERIALS AND METHODS}

\section{Materials}

The main material Amomum compactum seeds were obtained from local suppliers in Bantul Regency, Yogyakarta, Indonesia. Chemicals and other materials used were: Tween 80 (Kao Indonesia Chemical, Bekasi, Indonesia), polyethylene glycol 400/PEG 400 (idCHEM Co., Ltd., Kyunggi, South Korea), virgin coconut oil (Healthy Co, Yogyakarta, Indonesia), sunflower oil, corn oil, canola oil, and soybean oil. Artificial gastric fluid (AGF) consisted of distilled water (Brataco, Yogyakarta, Indonesia), hydrochloric acid 37\%, and $\mathrm{NaCl}$ (Merck, Germany).

\section{Methods}

\section{The essential oil extraction}

The extraction technique of Amomum compactum seed essential oil was prepared with steam distillation method. A kilogram of Amomum compactum seeds was loaded into the still distillation tank and eight liters of water were added. The rid secured tightly to steam distillation with the collection of the oils starting after a heating time of 30-50 minutes.

\section{Formulation of SNEDDS}

\section{Selection of carrier oil}

The solubility of Amomum compactum seed essential oil in carrier oil was determined. Virgin coconut oil (VCO), sunflower oil, corn oil, canola oil, and soybean oil were screened. Total $4 \mathrm{ml}$ Amomum compactum essential oil was continually added to $10 \mathrm{ml}$ carrier oil with vigorous vortex and continued with visual observation.

\section{SNEDDS preparation}

SNEDDS were prepared by mixing various combinations of Amomum compactum oil with a carrier oil (virgin coconut oil), Tween 80, and PEG 400. The formulations were subjected to sonication using ultrasonicator (J.P Selecta, Barcelona, Spain) for 10 minutes and water bath (Memmert GmbH \& Co.KG, Schwabach, Germany) at $37^{\circ} \mathrm{C}$ for 15 minutes (Abouelkassem et al., 2015).

\section{Percent transmittance}

The sample was prepared by mixing $0.1 \mathrm{ml}$ of SNEDDS with $5 \mathrm{ml}$ distilled water using vortex for 30 seconds. UV spectrophotometer was used to measure the percent transmittance at $650 \mathrm{~nm}$ (Sharma et al., 2012).

\section{Emulsification time}

Each formulation was dropped wise added to $500 \mathrm{ml}$ of artificial gastric fluid of $\mathrm{pH} 2$ in separate glass beakers at 37 $\pm 2^{\circ} \mathrm{C}$ and contents were gently stirred using magnetic stirrer at $100 \mathrm{rpm}$. Depending on visual appearance and time taken for selfemulsification (Khan et al., 2015).

VCO as a carrier oil, surfactant (Tween 80), and co-surfactant (PEG 400) in different ratios, SNEDDS with good emulsification and solubility characterization were selected (Ansari et al., 2014). The transmittance values of formulation above $90 \%$ indicate the self-nano emulsification efficiency of the SNEDDS (Narkhede et al., 2014). Ratio 1:4:1 (oil: surfactant: co-surfactant) was chosen for development formulation. When it reaches oil phase, essential oil was added.

\section{Optimization of SNEDDS}

The subsequent experimental study was determined made from the three-component system: $X_{1}$ the oil phase (a mixture of Amomum compactum essential oil and VCO, 1:1 v/v), $X_{2}$ the surfactant (Tween 80), and $X_{3}$ the co-surfactant (PEG 400). The responses $\left(Y_{1}=\right.$ emulsification time, $Y_{2}=$ transmittance) were interpreted by Design Expert ${ }^{\circledR}$ software version 7.1.5. (Stat-Ease, Minneapolis, MN). The results of SNEDDS were reproduced in three replicates for emulsification time and transmittance. The data were analyzed with single sample t-test analysis.

\section{Characterization of SNEDDS}

\section{Droplet size measurement}

Droplet size and polydispersity index of nanoemulsion were determined using Zetasizer Nano ZS (Horiba Scientific SZ-100, Horiba, Kyoto, Japan). The samples were diluted with a ratio of 1: $100(\mathrm{v} / \mathrm{v})$ using distilled water and repeated in triplicate (Balakumar et al., 2013).

\section{Zeta potential analysis}

Zeta potential of the optimum formulations was determined by dynamic light scattering using particle size analyzer (Horiba Scientific SZ-100, Horiba, Kyoto, Japan). The samples were diluted with a ratio of $1: 100(\mathrm{v} / \mathrm{v})$ with distilled water and repeated in triplicate (Balakumar et al., 2013).

\section{Viscosity measurement}

The viscosity of SNEDDS was measured using small sample adapter of Brookfield cone and plate rheometer (Model LV2, Brookfield Engineering Laboratories, Stoughton, MA, USA) $12 \mathrm{rpm}$ at room temperature $\left(25 \pm 1^{\circ} \mathrm{C}\right)$, repeated in triplicate (Sakulku et al., 2009).

\section{Thermodynamic stability studies}

The optimum formula was subjected to further thermodynamic stability studies.

(1) Heating-cooling cycle: Six cycles between $4^{\circ} \mathrm{C}$ and $45^{\circ} \mathrm{C}$ at each temperature for not less than 48 hours were studied. The formulations that passed at this temperature without any signs of instability (creaming, cracking) were subjected to centrifugation test.

(2) Centrifugation: The formulations were centrifuged for 30 minutes at $3500 \mathrm{rpm}$. The formulations that did not show any signs of instability (creaming, cracking) were chosen for the freeze-thaw cycle. 
(3) Freeze-thaw cycle: The formulations were placed in temperatures between $-21^{\circ} \mathrm{C}$ and $25^{\circ} \mathrm{C}$ with storage at each temperature for not less than 48 hours. Passed formulations were centrifuged 5 minutes at $3000 \mathrm{rpm}$ (Shafiq et al., 2007; Parmar et al., 2011).

\section{The morphology of SNEDDS}

The SNEDDS morphology was observed by Transmission Electron Microscopy Joel JEM-100 CX (Joel, Tokyo, Japan). The SNEDDS samples were diluted with water (1: 1000 ), a sample drop was stained with $2 \%$ phosphotungstic acid solution for $30 \mathrm{~s}$ and placed on a copper grid (Zhao et al., 2010).

\section{RESULTS}

\section{Formulation of SNEDDS}

\section{Selection of carrier oil}

The solubility of essential oil in the oil phase was important to keep the active components in the solubilized form and it also avoiding the deposition of the active component of emulsification in the intestinal lumen. The higher of solubility causes the required quantity of oil in the formulation is low and consequently, the amount of surfactant and co-surfactant required for emulsification time is low. It was observed that the solubility of Amomum compactum essential oil was higher in VCO in comparison to sunflower oil, corn oil, canola oil, and soybean oil (Table 1). The solubility essential oil in VCO was more clearly than sunflower oil, corn oil, canola oil, and soybean oil. VCO has a much shorter chain of $\mathrm{C}$ atoms compare with other vegetable oil, so making good solubility and become more transparent (Tristiana et al., 2014).
Table 1: Solubility study of Amomum compactum essential oil.

\begin{tabular}{cc}
\hline Carrier oil & Visual observation \\
\hline VCO & Clearly \\
Sunflower oil & Cloudy \\
Corn oil & Cloudy \\
Canola oil & Cloudy \\
Soybean oil & Cloudy \\
\hline
\end{tabular}

\section{SNEDDS preparation}

The compatibility of oils, surfactants, and co-surfactants to acquire a higher transmittance was the essential foundation in the fabrication of nanoemulsion. The preliminary ratio was tested to determine the quantity of oil (virgin coconut oil), surfactant (Tween 80), and co-surfactant (PEG 400) for further characterization. The effect of surfactant ratio on transmittance is presented in Table 2. Furthermore, the result (Table 3) could be used as a reference for optimization and treatment 2 was chosen.

Table 2: The effect of surfactant ratio on transmittance.

\begin{tabular}{cccc}
\hline Oil $(\mathbf{m l})$ & Surfactant $(\mathbf{m l})$ & Co-surfactant $(\mathbf{m l})$ & Transmittance $(\%)$ \\
\hline 1 & 1 & 1 & $9.37 \pm 5.27$ \\
1 & 2 & 1 & $55.00 \pm 2.05$ \\
1 & 3 & 1 & $70.40 \pm 13.36$ \\
1 & 4 & 1 & $98.43 \pm 0.85$ \\
1 & 5 & 1 & $98.73 \pm 0.92$ \\
1 & 6 & 1 & $99.13 \pm 0.67$ \\
1 & 7 & 1 & $98.60 \pm 0.36$ \\
\hline
\end{tabular}

Table 3: The addition of essential oil in the oil phase.

\begin{tabular}{|c|c|c|c|c|c|c|c|}
\hline Treatment & $\operatorname{VCO}(\mathrm{ml})$ & Essential oil (ml) & Tween 80 (ml) & PEG $400(\mathrm{ml})$ & Transmittance (\%) & Visual observation & Emulsification time (s) \\
\hline 1 & 0.75 & 0.25 & 4 & 1 & 99.57 & Transparent & 57.9 \\
\hline 2 & 0.5 & 0.5 & 4 & 1 & 99.4 & Transparent & 61.7 \\
\hline 3 & 0.25 & 0.75 & 4 & 1 & 98.63 & Cloudy & 76.16 \\
\hline
\end{tabular}

\section{Formulation optimization of SNEDDS}

The optimization formula has aimed to determine the levels of the variables from which product has the best quality. By means of the response surface methodology the influence of three independent variables (the amount of oil, Tween 80 , and PEG 400) in two dependent variables (emulsification time and transmittance). The selected formulation was based on the "trading off" of various response variables, i.e. maximizing the percent of transmittance and minimizing the emulsification time.

The formula 1: 4: 1 was used as the basis for finding the optimal formula. The comparison range of oil component: Tween 80: PEG 400 is 1: 3: 1 and 1: 5: $1(\mathrm{v} / \mathrm{v})$, respectively. The data were used to determine the lower limit and upper limit as in Table 4. In this optimization, D-optimal mixture design was used to find the optimal formula on various formulas made (Table 5). The response was transmittance and emulsification time. The analysis of variance and lack of fit tests are presented in Table 6.
The value of emulsification time was illustrated by colors that follow the spectrum of light (Wiwiek et al., 2017). The high emulsification time value is indicated by increasingly close to red. Figure 1(a) presents a normal probability plot residuals for emulsification time. The straight line represents normally distributed residuals and there was no evidence to indicate the possibility of outliers. (b) The data is around the 0 line and no one stands out.

Table 4: Ranges of the factors investigated using D-Optimal mixture design.

\begin{tabular}{ccc}
\hline \multirow{2}{*}{ Independent variables (factors) } & \multicolumn{2}{c}{ Range } \\
\cline { 2 - 3 } & Low & High \\
\hline$X_{1}=$ Quantity of oil & 14.29 & 20 \\
$X_{2}=$ Quantity of Tween 80 & 60 & 71.43 \\
$X_{3}=$ Quantity of PEG 400 & 14.29 & 20 \\
\hline
\end{tabular}

The model (Figure 2) showed the significant $(\mathrm{p}<0.05)$ relationship between the quantity (oil, Tween 80 , PEG 400) and 
the response (emulsification time). The lack of fit analysis (Table 6) showed no significant $(p>0.05)$ means there had a high match between predicted value and actual data.

Table 5: Formulation design (Design Expert ${ }^{\circledR}$ Ver. 7.1.5.).

\begin{tabular}{|c|c|c|c|c|c|}
\hline Run & Oil component (\%) & Tween $80(\%)$ & PEG $400(\%)$ & Transmittance (\%) & Emulsification time (s) \\
\hline 1 & 17.737 & 67.973 & 14.290 & 99.6 & 53.48 \\
\hline 2 & 14.607 & 66.947 & 18.446 & 99.7 & 51.36 \\
\hline 3 & 14.293 & 71.417 & 14.290 & 99.9 & 42.43 \\
\hline 4 & 20.000 & 60.005 & 19.995 & 99.8 & 74.40 \\
\hline 5 & 20.000 & 60.005 & 19.995 & 99.1 & 75.17 \\
\hline 6 & 14.293 & 71.417 & 14.290 & 99.1 & 49.00 \\
\hline 7 & 16.764 & 66.028 & 17.208 & 99.8 & 42.89 \\
\hline 8 & 20.000 & 65.220 & 14.780 & 99.8 & 65.00 \\
\hline 9 & 17.493 & 62.507 & 20.000 & 99.6 & 70.94 \\
\hline 10 & 17.454 & 64.168 & 18.378 & 99.8 & 43.17 \\
\hline 11 & 14.986 & 65.014 & 20.000 & 99.6 & 48.03 \\
\hline 12 & 14.449 & 68.774 & 16.777 & 99.9 & 53.74 \\
\hline 13 & 14.986 & 65.014 & 20.000 & 99.5 & 49.33 \\
\hline 14 & 20.000 & 62.616 & 17.384 & 99.6 & 61.64 \\
\hline 15 & 17.737 & 67.973 & 14.290 & 99.8 & 55.64 \\
\hline 16 & 20.000 & 65.220 & 14.780 & 99.5 & 57.80 \\
\hline
\end{tabular}

Table 6: Analysis of the Quadratic Model.

\begin{tabular}{ccc}
\hline Response & $F$ value & Probability $>F$ \\
\hline$Y_{1}=$ Emulsification time & & \\
Model & 7.94 & 0.0034 significant \\
Lack of fit & 0.85 & 0.5496 nonsignificant \\
$Y_{2}=$ Transmittance & & \\
Model & 2.82 & 0.0959 nonsignificant \\
Lack of fit & 0.87 & 0.5907 nonsignificant \\
\hline
\end{tabular}

Emulsification time was known as a great importance parameter for describe the stability of the system and prepare emulsification in gastric fluid of SNEDDS self-emulsifying characteristics (Singh et al., 2011). Tween 80 as a non-ionic surfactant were found to have good solubility and better emulsification ability, that allowed rapid dispersion when in contact with biological fluids (Sanka et al., 2016). As shown in Figure 2, the time required for emulsification decreases with the increased concentration of Tween 80 . PEG 400 commonly use in nanoemulsion formulation to increase solubility and bioavailability (Nekkanti et al., 2011).

\section{Percent transmittance}

Percent of transmittance was used to observe the selfemulsification process by measuring the transmittance of the solution during dissolution as the emulsification process happened (Villar et al., 2012).

The value of the transmittance was illustrated by colors that follow the spectrum of light (Wiwiek et al., 2017). The higher transmittance value indicated more approach to red. Figure 3(a) presented a normal probability plot residuals for transmittance. The straight line showed normally distributed residuals and there was no evidence to indicate the possibility of outliers. (b) The data is around the 0 line and no one stands out.
The special cubic model (Figure 4) showed that there was no significant $(p>0.05)$ relationship between the quantity (oil, Tween 80, PEG 400) and the response (transmittance). The lack of fit analysis (Table 6) resulted not significant $(p>0.05)$ means there was a high match between predicted value and actual data.

Based on Figure 5, the recommended optimum formula was $20 \%$ oil, $65.71 \%$ Tween 80 , and $14.29 \%$ PEG 400 with desirability 0.790 .

The result of the optimum formula was verified with single sample t-test with OpenStat ${ }^{\circledR}$ (Table 7). The p-value of emulsification time was higher than 0.05 which implied that there was no significant difference between predicted value and actual data (Winarti et al., 2017).

Table 7. Verification of optimum formula with single sample t-test.

\begin{tabular}{cccc}
\hline Response & Predicted value & Actual data \pm SD & p-value \\
\hline Emulsification time & 45.049 & $46.38 \pm 0.61$ & 0.065 \\
Transmittance & 99.151 & $99.37 \pm 0.06$ & 0.023 \\
\hline
\end{tabular}

\section{Characterization of SNEDDS}

\section{Droplet size}

The mean droplet size and polydispersity-index (PI) were calculated from volume, intensity, and bimodal distribution assuming spherical particles. PI was a measure of particle homogeneity (Patel et al., 2010). The particle size distribution of the selected formulation was found to be $13.97 \pm 0.31 \mathrm{~nm}$, which was highly desirable. The polydispersity-index (PI) was low $(0.06 \pm 0.05)$, indicating that the system had narrow size distribution. The droplet size was an important factor in SNEDDS formulation, as this determines the rate and extent of drug release as well as absorption and improve bioavailability (Parmar et al., 2011). The oil phase positively influenced the formation of droplet 
size (Shanmugam et al., 2011). The addition of surfactants to the nanoemulsion systems caused the interfacial film to stabilize and condense (Villar et al., 2012).

\section{Emulsification Time}

\section{Color points by value of Emulsification Time: \\ 89.45 \\ 43.56}

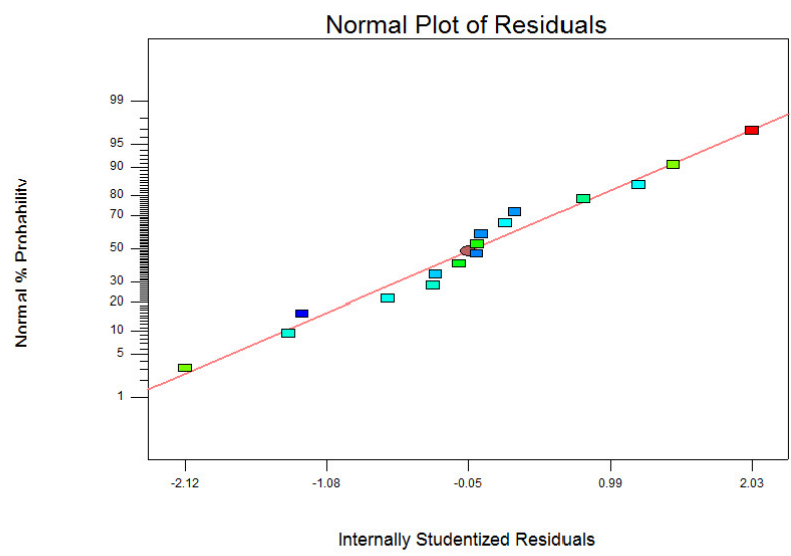

(a)

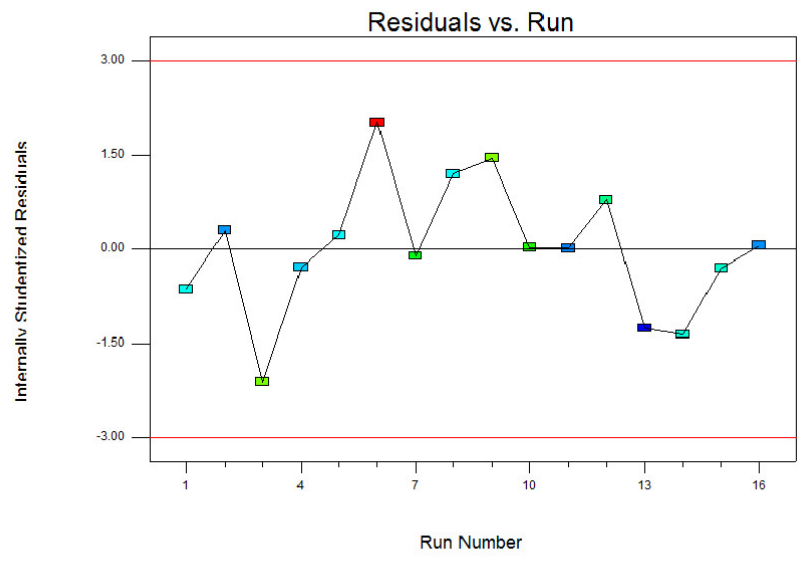

(b)

Fig. 1: Graph of a residual parameter of emulsification time (Design Expert ${ }^{\circledR}$ Ver. 7.1.5.).

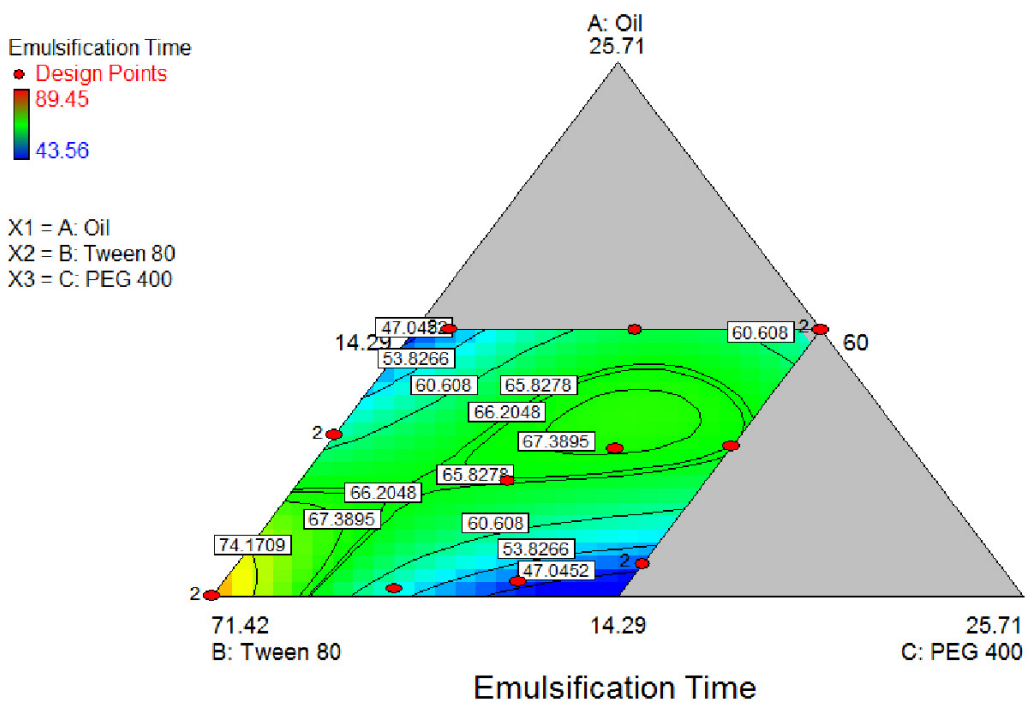

Fig. 2: Special model cubic of emulsification time graphic values (Design Expert ${ }^{\circ}$ Ver. 7.1.5.)

\section{Zeta potential}

Zeta potential values of the selected formulation were found in the range of -28.8 to $-45.9 \mathrm{mV}$. The high negative charge was probably due to the presence of free fatty acids present in the formulation (Balakumar et al., 2013). Zeta potential values which were less $-30 \mathrm{mV}$ or greater than $30 \mathrm{mV}$ indicated a stable nanoemulsion (Yang and Benita, 2000). Therefore, the results of zeta potential measurement indicated stable SNEDDS formulation.

\section{Viscosity measurement}

The viscosity of the selected formulation was found to be $187.5 \pm 0 \mathrm{mPa}$.s. The viscosity of Tween 80 was high (425 mPa.s) so the inclusion of PEG 400 could improve the self-emulsification (Rowe et al., 2009). The lower viscosity of SNEDDS mainly due to the smaller droplet size (Shakeel et al., 2013). 
Color points by value of

Transmittance

99.4

98.7

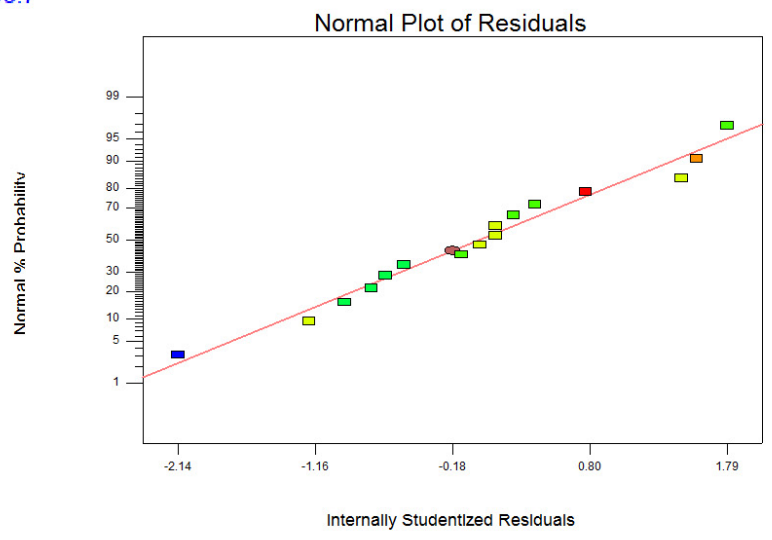

(a)

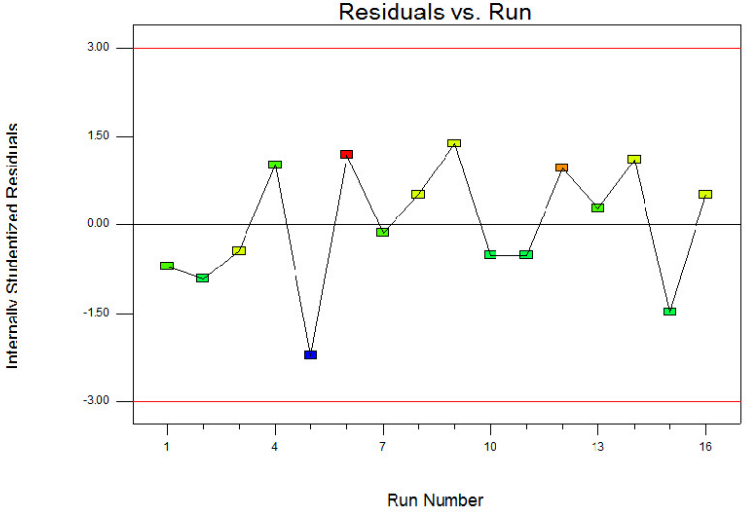

(b)

Fig. 3: Graph of a residual parameter of transmittance (Design Expert ${ }^{\circledR}$ Ver. 7.1.5.).

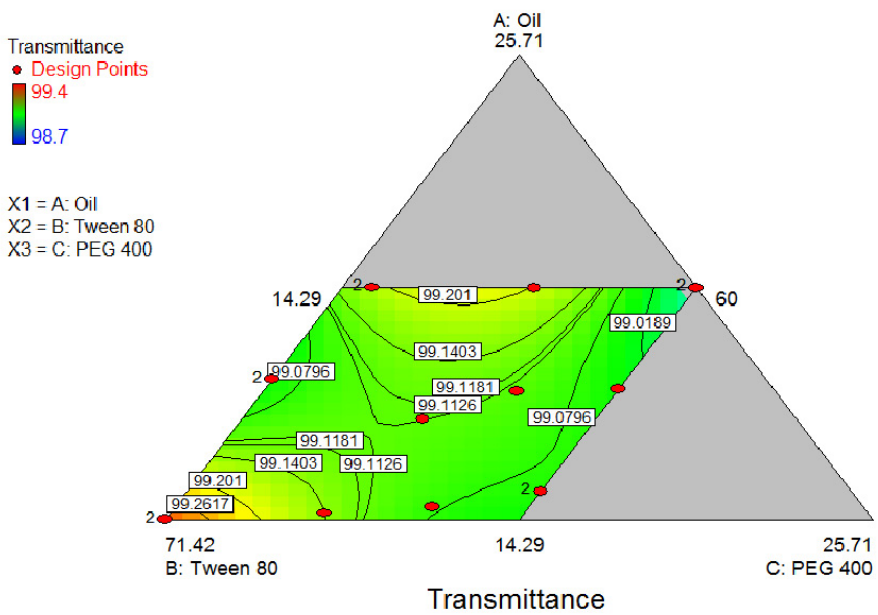

Fig. 4: Special model cubic of transmittance graphic values (Design Expert@ Ver. 7.1.5.).

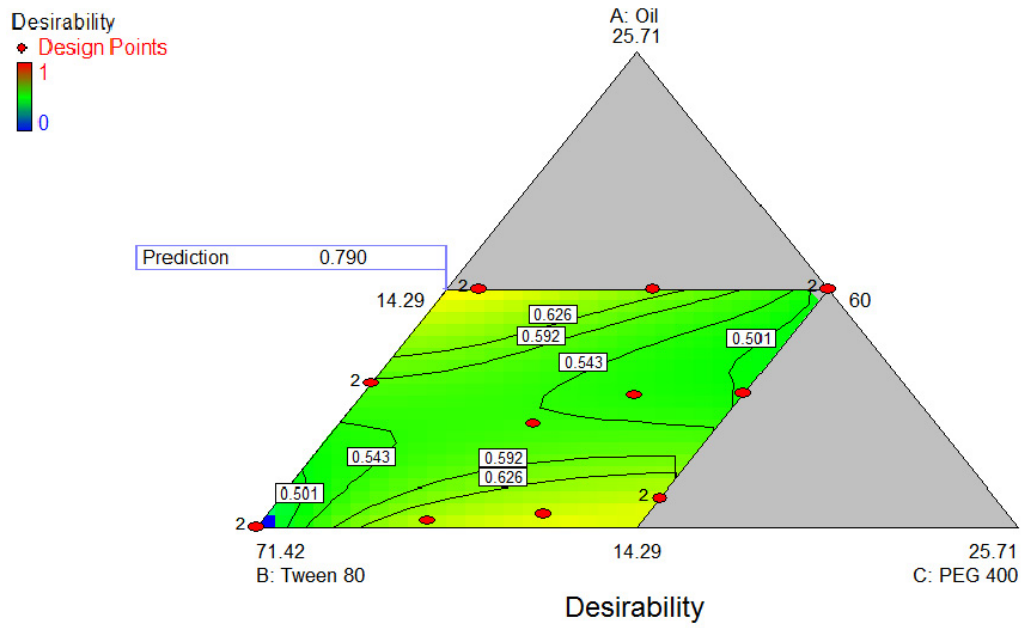

Fig. 5: Superimposed of special model cubic emulsification time and transmittance. 


\section{Thermodynamic stability}

It was observed that the optimum formulation passed the thermodynamic stress tests (Table 8). The optimum formulation did not show any signs of instability indicated stability of the system. The system of SNEDDS should be spontaneous emulsification in the intestinal tract to form a nanoemulsion. The SNEDDS system must have sufficient quality to withstand stability in order to restrain creaming, cracking, or precipitating. The selected formulation was subjected to heating-cooling cycle, centrifugation, and freeze-thaw cycle exposure (Bandyopadhyay et al., 2012).

Table 8: Thermodynamic stability test.

\begin{tabular}{cccc}
\hline Stability test & Replication 1 & Replication 2 & Replication 3 \\
\hline Heating-cooling cycle & $\sqrt{ }$ & $\sqrt{ }$ & $\sqrt{ }$ \\
Centrifugation & $\sqrt{ }$ & $\sqrt{ }$ & $\sqrt{ }$ \\
Freeze-thaw cycle & $\sqrt{ }$ & $\sqrt{ }$ & $\sqrt{ }$ \\
\hline
\end{tabular}

Transmission electron microscopy (TEM)

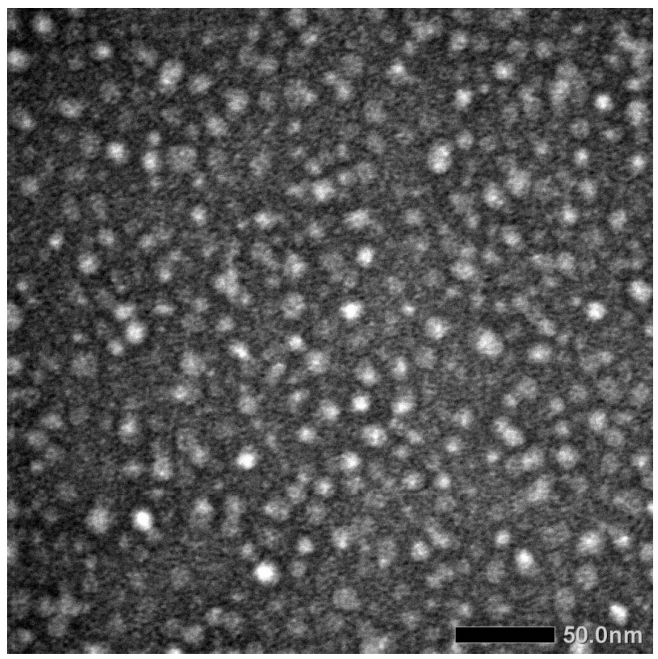

Fig. 6: Transmission electron micrograph of SNEDDS with magnification $80 \mathrm{~K}$.

The nanoemulsion appeared a bright spot on a dark background with a spherical shape which homogenous droplet size (Figure 6). Different and non-aggregated nanoemulsion droplets indicated physically stable nanoemulsion (Badran et al., 2014).

\section{CONCLUSION}

SNEDDS of Amomum compactum essential oil could be formulated with ratio $10 \%$ of Amomum compactum essential oil, $10 \%$ of virgin coconut oil, $65.71 \%$ of Tween 80 , and $14.29 \%$ of PEG 400 . The formulation had a high percent transmittance $99.37 \pm 0.06$, low emulsification time $46.38 \pm 0.61 \mathrm{~s}$, small droplet size $13.97 \pm 0.31 \mathrm{~nm}$ with PI $0.06 \pm 0.05$, stable zeta potential -28.8 to $-45.9 \mathrm{mV}$, low viscosity $187.5 \pm 0 \mathrm{mPa} . \mathrm{s}$, passed the thermodynamic stability tests, and spherical shape. The study revealed that the formulation could improve the water solubility and stability of Amomum compactum essential oil. Optimizing this formula may permit its use as an antibacterial and potentially be used as an alternative to the antibiotic in poultry production.

\section{CONFLICT OF INTEREST}

All contributing authors report no conflict of interest.

\section{ACKNOWLEDGMENTS}

Authors would like to acknowledge Biopharmaceutics Laboratory, Department of Pharmaceutics, Faculty of Pharmacy, Universitas Gadjah Mada Yogyakarta for providing facilities in this study. We also would like to address a gratitude to DIKTI Ministry of Research, Technology, and Higher Education Indonesia for the funding to conduct a significant part of the study.

\section{REFERENCES}

Abouelkassem Sh, Abdelrazeik AB, Rakha OM. Nanoemulsion of jojoba oil, preparation, characterization and insecticidal activity against Sitophilus oryzae (coleoptera: curculionidae) on wheat. International Journal of Agriculture Innovations and Research, 2015; 4:72-75.

Akthar MS, Degaga B, Azam T. Antimicrobial activity of essential oils extracted from medicinal plants against the pathogenic microorganisms: a review. Issues in Biological Sciences and Pharmaceutical Research, 2013; 2:001-007.

Ansari KA, Pagar KP, Anwar S, Vavia PR. Design and optimization of self-microemulsifying drug delivery system (SMEDDS) of felodipine for chronotherapeutic application. Brazilian Journal of Pharmaceutical Sciences, 2014; 50:203-212.

Apata DF. Antibiotic Resistance in poultry. International Journal of Poultry Science, 2009; 8:404-408.

Badran MM, Taha EI, Tayel MM, Al-Suwayeh SA. Ultra-fine self nanoemulsifying drug delivery system for transdermal delivery of meloxicam: dependency on the type of surfactants. Journal of Molecular Liquids, 2014; 190:16-22.

Balakumar K, Raghavan CV, Selvan NT, Prasad RH, Abdu S. Self nanoemulsifying drug delivery system (SNEDDS) of rosuvastatin calcium: design, formulation, bioavailability and pharmacokinetic evaluation. Colloids and Surfaces B: Biointerfaces, 2013; 112:337-343.

Bandyopadhyay S, Katare OP, Singh B. Optimized self nanoemulsifying systems of ezetimibe with enhanced bioavailability potential using long chain and medium chain triglycerides. Colloids and Surfaces B: Biointerfaces, 2012; 100:50-61.

Dibner JJ, Richards JD, Knight CD. Microbial imprinting in gut development and health. Journal of Applied Poultry Research, 2008; 17:174-188

Tristiana E, Hendradi E, Soeratri W. Praformulation study of $p$-methoxycinnamic acid (PMCA) nanoemulsion using vegetable oils (soybean oil, corn oil, VCO). International Journal of Pharmaceutical Sciences, 2014; 6:99-101.

Huang Y, Fang J, Hung C, Wu P, Tsai Y. Cyclic monoterpene extract from cardamom oil as a skin permeation enhancer for indomethacin: in vitro and in vivo studies. Biological and Pharmaceutical Bulletin, 1999; 22:642-646.

Jamil B, Abbasi R, Abbasi S, Imran M, Khan SU, Ihsan A, Javed S, Bokhari H, Imran M. Encapsulation of cardamom essential oil in chitosan nano-composites: in-vitro efficacy on antibiotic-resistant bacterial pathogens and cytotoxicity studies. Frontiers in Microbiology, 2016; 7:110 .

Khan AW, Kotta S, Ansari SH, Sharma RK, Ali J. Selfnanoemulsifying drug delivery system (SNEDDS) of the poorly watersoluble grapefruit flavonoid Naringenin: design, characterization, in vitro and in vivo evaluation. Drug Delivery, 2015; 22:552-561.

Patel MJ, Patel NM, Patel RB, Patel RP. 2010. Formulation and evaluation of self-microemulsifying drug delivery system of lovastatin. Asian Journal of Pharmaceutical Sciences, 2010; 5:266-275.

Nanasombat S, Lohasupthawee P. Antibacterial activity of crude ethanolic and essential oils of spices against Salmonellae and other enterobacteria. KMTIL Science and Technology Journal, 2005; 5:527-538. 
Narkhede RS, Gujar KN, Gambhire VM. Design and evaluation of self-nanoemulsifying drug delivery systems for nebivolol hydrochloride. Asian Journal of Pharmaceutics, 2014; 8:200-209.

Natrajan D, Srinivasan S, Sundar K, Ravindran A. Formulation of essential oil-loaded chitosan-alginate nanocapsules. Journal of Food and Drug Analysis, 2015; 23:560-568.

Neethirajan S and Jayas DS. Nanotechnology for the food and bioprocessing industries. Food Bioprocess Technol, 2011; 4:39-47.

Nekkanti V, Venkateswarlu V, Ansari KA, Pillai R. Development and pharmacological evaluation of a PEG based nanoparticulate camptothecin analog for oral administration. Current Drug Delivery, 2011; 8:661-666.

Parmar N, Singla N, Amin S, Kohli K. Study of cosurfactant effect on nanoemulsifying area and development of lercanidipine loaded (SNEDDS) self nanoemulsifying drug delivery system. Colloids and Surfaces B: Biointerfaces, 2011; 86:327-338.

Pedro AS, Santo IE, Silva CV, Detoni C, Albuquerque E. The use of nanotechnology as an approach for essential oil-based formulations with antimicrobial activity. Current Research, Technology and Education Topics in Applied Microbiology and Microbial Biotechnology, 2013; 2:1364-1374.

Rowe RC, Sheskey PJ, Quinn ME. 2009. Handbook of Pharmaceutical Excipients (Sixth edition). London: Pharmaceutical Press.

Sakulku U, Nuchuchua O, Uawongyart N, Puttipipatkhachorn S, Soottitantawat A, Ruktanonchai U. Characterization and mosquito repellent activity of citronella oil nanoemulsion. International Journal of Pharmaceutics, 2009; 372:105-111.

Sanka K, Suda D, Bakshi V. Optimization of solid-self nanoemulsifying drug delivery system for solubility and release profile of clonazepam using simplex lattice design. Journal of Drug Delivery Science and Technology, 2016; 33:114-124.

Shafiq S, Shakeel F, Talegaonkar S, Ahmad FJ, Khar RK, Ali M. Development and bioavailability assessment of ramipril nanoemulsion formulation. European Journal of Pharmaceutics and Biopharmaceutics, 2007; 66:227-243.

Shakeel F, Haq N, Alanazi FK, Alsarra IA. Impact of various nonionic surfactants on self-nanoemulsification efficiency of two grades of Capryol (Capryol-90 and Capryol-PGMC). Journal of Molecular Liquids, $2013 ; 182: 57-63$.

Shanmugam S, Baskaran R, Balakrishnan P, Thapa P, Yong CS, Yoo BK. Solid self-nanoemulsiffying drug delivery system (S-SNEDDS) containing phosphatidylcholine for enhanced bioavailability of highly lipophilic bioactive carotenoid lutein. European Journal of Pharmaceutics and Biopharmaceutics, 2011; 79:250-257.

Sharma B, Sharma A, Arora S, Gupta S, Bishnoi M. Formulation, optimization and evaluation calcium loaded microemulsion. Journal of
Pharmaceutics and Drug Delivery Research, 2012; 1:1-7.

Singh B, Khurana L, Bandyopadhyay S, Kapil R, Katare OOP. Development of optimized self-nano-emulsifying drug delivery systems (SNEDDS) of carvedilol with enhanced bioavailability potential. Drug Delivery, 2011; 18:599-612.

Verstegen MWA and Williams BA. Alternatives to the use of antibiotics as growth promoters for monogastric animals. Animal Biotechnology, 2002; 13:113-127.

Villar AMS, Naveros BC, Campmany ACC, Trenchs MA, Rocabert CB, Bellowa LH. Design and optimization of self-nanoemulsifying drug delivery systems (SNEDDS) for enhanced dissolution of gemfibrozil. International Journal of Pharmaceutics, 2012; 431:161-175.

Winarti L, Ameliana L, Nurahmanto D. Formula optimization of orally disintegrating tablet containing meloxicam nanoparticles. Research Article, Indonesian Journal of Pharmacy, 2017; 28:53-64.

Wiwiek IA, Martodihardjo S, Soenardi, Jumina, Budiana IGMN, Mustofa. Preparation and in-vitro characterization of self-nano emulsifying system of C-Phenylcalix-[4]-Resorcynaryl Octacinnamate and C-Methylcalix-[4]-Resorcinaryl Octabenzoate as ultraviolet absorbers. Bali Medical Journal, 2017; 6:569-577.

Yang SC, Benita S. Enhanced absorption and drug targeting by positively charged submicron emulsion. Drug Development Research, 2000; 50:476-486.

Zeng Z, Zhang S, Wang H, Piao X. Essential oil and aromatic plants as feed additives in non-ruminant nutrition: a review. Journal of Animal Science and Biotechnology, 2015; 6:1-10.

Zengin $\mathrm{H}$, Baysal AH. Antibacterial and antioxidant activity of essential oil terpenes against pathogenic and spoilage-forming bacteria and cell structure-activity relationships evaluated by SEM microscopy. Molecules, 2014; 19:17773-17798.

Zhao Y, Wang C, Chow AHL, Ren K, Gong T, Zhang Z, Zheng Y. Self-nanoemulsifying drug delivery system (SNEDDS) for oral delivery of zedoary essential oil: formulation and bioavailability studies. International Journal of Pharmaceutics, 2010; 383:170-177.

How to cite this article:

Ujilestari T, Martien R, Ariyadi B, Dono ND, Zuprizal. Self-nanoemulsifying drug delivery system (SNEDDS) of Amomum compactum essential oil: Design, formulation, and characterization. J App Pharm Sci, 2018; 8(06): 014-021. 